\title{
Improved osteogenic activity and inhibited bacterial biofilm formation on andrographolide-loaded titania nanotubes
}

\author{
Eryou Feng ${ }^{1 \#}$, Kaiwei Shen ${ }^{1 \#}$, Feitai Lin ${ }^{1}$, Wentao Lin ${ }^{1}$, Tao Zhang ${ }^{1}$, Yiyuan Zhang ${ }^{1}$, Fengfei Lin ${ }^{2}$, \\ Yun Yang ${ }^{3}$, Changjian Lin ${ }^{4}$ \\ ${ }^{1}$ Department of Arthrosis Surgery, Fuzhou Second Hospital Affiliated to Xiamen University, Teaching Hospital of Fujian Medical University, \\ Fuzhou, China; ${ }^{2}$ Department of Orthopaedics, Fuzhou Second Hospital Affiliated to Xiamen University, Teaching Hospital of Fujian Medical \\ University, Fuzhou, China; ${ }^{3}$ Research Institute for Biomimetics and Soft Matter, Fujian Provincial Key Laboratory for Soft Functional Materials \\ Research, College of Physical Science and Technology, Xiamen University, Xiamen, China; ${ }^{4}$ State Key Laboratory of Physical Chemistry of Solid \\ Surfaces, and Department of Chemistry, College of Chemistry and Chemical Engineering, Xiamen University, Xiamen, China \\ Contributions: (I) Conception and design: E Feng, F Lin; (II) Administrative support: Y Zhang, Y Yang; (III) Provision of study materials or patients: \\ K Shen, W Lin; (IV) Collection and assembly of data: T Zhang, F Lin, C Lin; (V) Data analysis and interpretation: All authors; (VI) Manuscript \\ writing: All authors; (VII) Final approval of manuscript: All authors. \\ \#These authors contributed equally to work. \\ Correspondence to: Eryou Feng. Department of Arthrosis Surgery, Fuzhou Second Hospital Affiliated to Xiamen University, No. 47, Shangteng \\ Road, Cangshan District, Fuzhou, China. Email: fey9001@126.com; Fengfei Lin. Department of Orthopaedics, Fuzhou Second Hospital Affiliated \\ to Xiamen University, No. 47, Shangteng Road, Cangshan District, Fuzhou, China. Email: 596558644@qq.com; Yiyuan Zhang. Department \\ of Arthrosis Surgery, Fuzhou Second Hospital Affiliated to Xiamen University, No. 47, Shangteng Road, Cangshan District, Fuzhou, China. \\ Email: 2311800579@qq.com.
}

Background: Delivery of local drugs with a titania nanotube is an attractive approach to combat implantrelated infection. Our earlier study has confirmed that nanotubes loaded with gentamicin could significantly improve the antibacterial ability. On this basis, the used andrographolide in this paper has a high antibacterial activity, which cannot only avoid the evolution of antibiotic-resistant bacteria but also has simultaneously excellent biocompatibility with osteogenic cells.

Methods: Two mg of andrographolide was loaded into titania nanotubes, which were fabricated into different diameters (50 and $100 \mathrm{~nm}$ ) and $200 \mathrm{~nm}$ length by the method of lyophilization and vacuum drying. We chose a standard strain, Staphylococcus epidermidis (American Type Culture Collection 35984), and two clinical isolates, S. aureus 376 and S. epidermidis 389 to research the bacterial adhesion at 6, 12 and 24 hours and biofilm formation at 48 , and 72 hours on the andrographolide-loaded nanotubes (NT-A) using the diffusion plate method. Smooth titanium (smooth Ti) and nanotubes with no drug loading (NT) were also inclusive and analyzed. Furthermore, the Sprague-Dawley (SD) rats mesenchymal stem cells were used to assess the influence of nanotubular topographies on the osteogenic differentiation of mesenchymal stem cells.

Results: Our results showed that NT-A could inhibit bacterial adhesion and biofilm formation on implant surfaces. NT-A and NT, especially those with $100 \mathrm{~nm}$ diameters, were found to significantly promoted cell attachment, proliferation, diffusion, and osteogenic differentiation when compared with smooth Ti, while the same diameter in NT-A and NT did not differ.

Conclusions: Titania nanotube modification and andrographolide loading can significantly improve the antibacterial ability and osteogenic activity of orthopedic implants. Nanotubes-based local delivery could be a promising strategy for combating implant-associated infection.

^ ORCID: 0000-0002-2243-7700. 
Keywords: Andrographolide; bacteria adhesion; biofilm formation; implant-associated infection; titania nanotubes

Submitted May 01, 2020. Accepted for publication Aug 05, 2020.

doi: 10.21037/atm-20-4901

View this article at: http://dx.doi.org/10.21037/atm-20-4901

\section{Introduction}

Biomaterial-involved infection is one of the most devastating complications after prosthesis implantation (1). Despite rigorous sterilization procedures, the infection rates of primary total joint replacement are still as high as $1-4 \%(2)$. Systemic antibiotic intervention and topical administration are the two leading approaches to prevent and treat implant-related infections. However, to the former, topical administration is considered safer and more effective (3).

Titania nanotubes (TNTs) have become conspicuous due to their low coefficients of elasticity and distinct topography $(4,5)$. The preparation of titania nanotube arrays based on electrochemical anodization of Ti implants has attracted much attention with controllable nano-structure same to natural bone and excellent biological performance (6). TNTs not only provide natural antibacterial properties, but constitute an excellent drug delivery system, and their results in enhancing osseointegration in vivo are quite satisfactory in orthopedic prostheses and joint replacements, as well as other biomedical fields (7). Therefore, from TNTS, local drug delivery was regarded as a promising preventing strategy for implantable infections (8-12). Popat et al. (13) have demonstrated the elution of gentamicin, which was loaded in nanotube to reduce the bacteria's sticking on its face. In the former essay, we studied the ability of antibacteria of gentamicin-loaded nanotubes (NT-G) indistinct sizes. It is discovered that NT-G could restrain bacterial sticking on its outer layer and the shaping of biofilm. However, abuse of antibiotics has accelerated the ongoing antibiotic-bearing bacteria, particularly methicillin-bearing Staphylococcus aureus (MRSA), and the gentamicinheld nanotubes do not often make sense (14-16). MRSAs can control $\beta$-lactam antibiotics (oxacillin, penicillin, and amoxicillin), which contain third-era cephalosporins, streptomycin, tetracycline, and sulfonamides; and when touching vancomycin and other glycopeptide antibiotics, some MRSA bearing becomes less sensitive to these antibiotics (17). Implant-involved infections became harder to treat with the emergence of resistant strains.
Also, according to previous vitro and vivo researches, gentamicin at considerable neighborhood focus decreased the change, productivity, and alkaline phosphatase event of the osteoblasts (18-20), and restrained the productivity and specification of man's body proliferation and differentiation of human bone marrow mesenchymal stem cells $(21,22)$, impairing the body-recovering procedure. In this way, to combat antibiotic-resistant bacteria, it is inevitable to research a securer and practical antimicrobial agent that could be loaded into the nanotubes. Andrographolide (C20H30O5), a diterpenoid lactone, has been investigated with modern drug discovery method for anti-inflammatory effects since 1984, and has been shown to possess anti-viral, anti-thrombotic, hepatoprotective, anti-cancer and antiinflammatory properties. It is the main active component of the genus Andrographis (family Acanthaceae), which is a part of the traditional herbal medicine and widely used for the treatment of flu (23). A previous study successfully synthesized a new water-soluble andrographolide derivative with the improved antibacterial ability and significantly reduced cytotoxicity (24). Due to their good safety profile and encouraging effectiveness in anti-inflammatory, andrographolide and its analogs have great potential to be the next new class of anti-inflammatory agents $(25,26)$.

A prospective purpose of andrographolide is placing it into nanotubes to release a suitable quantity of antibacterial substance at once to enter substance face to remove planktonic bacteria, stopping bacterial sticking and biofilm shaping. The novelty of this work is to exploit the excellent biocompatibility and enhanced osseointegration of titania nanotube loaded with good safety profile and anti-inflammatory andrographolide as an innovative delivery system. To the best of our knowledge, although titania nanotube has been widely used in biomedical fields, but yet there is no published work on andrographolideloaded titania nanotubes for implant-related infection prevention. In our research, the antibacterial function, especially the ability to inhibit biofilm formation of various diameter andrographolide loaded (NT-A) and nonloaded nanotubes (NT), were investigated. Staphylococcus aureus, Methicillin-resistant Staphylococcus aureus, and 
Staphylococcus epidermidis lead to $66 \%$ of catastrophic orthopedic implant-involved infections (27). In this way, we chose a criteria control, Staphylococcus epidermidis [American Type Culture Collection (ATCC)35984] and two treatment separation, S. aureus 376 and S. epidermidis 389 in this procedure, and the three bacterial strains had biofilm-forming features $(28,29)$.

We present the following article in accordance with the MDAR reporting checklist (available at http://dx.doi. org/10.21037/atm-20-4901).

\section{Methods}

\section{Manufacture of TNTs samples}

Before the electronic and chemical anodic oxidation, neat Ti plates of $99.5 \%$ density $(10 \mathrm{~mm}$ in inner length and $1 \mathrm{~mm}$ in height) were treated with acetone by ultrasound to end facial fuel stains. Later, the 60 s of Chemical polishing was carried on in the mixed material, including $\mathrm{HNO} 3$ and $\mathrm{HF}(\mathrm{V}(\mathrm{HNO} 3): \mathrm{V}(\mathrm{HF})=1: 1$ and later removed with deionized liquid. The anodization disposes was conducted in traditional two-electrode body tissue. Pure Ti plates functioned as the anode electrode, and platinum plates served as the cathode electrode. Zero point five wt $\%$ ammonium fluoride (NH4F) and 10 vol\% distilled water in ethylene glycol consisted of the electrolyte. After anodization for $1 \mathrm{~h}$ at a continuous voltage of $15,20 \mathrm{~V}$, TNTs with diameters of 50 and $100 \mathrm{~nm}$, that is, were manufactured on the Ti plates. Later, the samples were removed with deionized liquid and dehydrated. All the samples were manufactured at a certain temperature of the housing. The facial topographies of the TNTs with various inner length were investigated with a camera electron scanning machine. Andrographolide was bought from Sigma-Aldrich (St. Louis, MO, USA). Smooth titanium (smooth $\mathrm{Ti}$ ) plates were selected as a restrain group in all tests. Both parts of the samples were sterilized by UV shining before performing the antibacterial and cell-culture tests.

\section{Loading of andrographolide}

Andrographolide was put in the nanotubes by a desivac approach and vacuum machine to dry $(13,30,31)$. In short, we prepared the $20 \mathrm{mg} / \mathrm{mL}$ andrographolide solution in deionized water and used the deionized water to clean the surfaces of the TNTs before andrographolide holding.
Later, $10 \mu \mathrm{L}$ of andrographolide substance was transferred into the nanotubes faces with a pipette and mildly transported to guarantee enough contact interface. The samples were then dried in a vacuum machine at $-45^{\circ} \mathrm{C}$ for $2 \mathrm{~h}$. The above holding procedure was recycled until $2 \mathrm{mg}$ of andrographolide was loaded into the nanotubes. After all the drying steps were completed, $1 \mathrm{~mL}$ of phosphatebuffered saline (PBS) was utilized with a pipette to wash the surfaces rapidly to take away any over andrographolide. The washing material was kept for ongoing study. The amount of andrographolide loaded into nanotubes was performed by using an indirect method by subtracting the amount of andrographolide free (unentrapped drug) quantified in the supernatant after loading of the TNTs by the desivac method and vacuum drying from the mg total of andrographolide used in the preparation of TNTs (initial drug amount) (32). Andrographolide quantifications were carried out on a high-performance liquid chromatography (HPLC) method. The concentration of andrographolide loaded into nanotubes was calculated by using Equations: drug loading $(\mathrm{DL} \%)=($ initial drug amount - unentrapped drug $) /($ weight of TNTs $) \times 100 \%$.

\section{Characterization of drug release from TNTs}

The launch dynamics of andrographolide in the nanotubes were obtained by high-performance liquid chromatography (HPLC) method. We separately soaked each of the three plates of NT-A with various diameters in $1 \mathrm{~mL}$ of PBS in a 48-well plate (Costar3548, Corning Company, Corning, NY, USA) at $37^{\circ} \mathrm{C}$ and shaken at $100 \mathrm{rpm}$. There was no parallel control to soak andrographolide-loaded nanotubes in $1 \mathrm{~mL}$ of PBS. Every time we collected the specimens, we used $1 \mathrm{~mL}$ of fresh PBS instead of the solution. All the specimens were collected at a specific middle period to obtain the launching and taken regularly for as much as 60 hours. The Agilent $\mathrm{C}_{18}$ column $(150 \mathrm{~mm} \times 4.6 \mathrm{~mm}, 5 \mu \mathrm{m})$ was used with the mobile phase of methanol-water (52:48). The flow rate of andrographolide was $0.8 \mathrm{~mL} / \mathrm{min}$, the testing length of wave $225 \mathrm{~nm}$. The injection quantity was $10 \mu \mathrm{L}$. The flow rate of dehydrographolide was $0.8 \mathrm{~mL} / \mathrm{min}$, the testing length of the wave was $254 \mathrm{~nm}$, and the area degree was $30^{\circ} \mathrm{C}$. The injection quantity was $10 \mu \mathrm{L}$. The amount of carbohydrate was determined within 60 hours.

\section{Preparation and characterization of bacteria}

Di Qu (Lab of Medical Molecular Virology, Shanghai 
Medical College, Fudan University, Shanghai, China) kindly afforded us S. epidermidis (ATCC35984). The treatment separation S. aureus 376 and S. epidermidis 389 were friendly supplied by Saïd Jabbouri (Université du Littoral Côte D'Opale, Boulognesur-Mer, France). Our former researches showed that the three tested strains were capable of biofilm-producing $(29,33)$. We stored these strains at $-80{ }^{\circ} \mathrm{C}$ as glycerol organizations. The restrains were bred quickly on tryptone soy agar (TSA) substance at $37^{\circ} \mathrm{C}$. A sterile $10 \mu \mathrm{L}$ loop was adopted to extract bacteria hostages from the TSA, which were then injected into $10 \mathrm{~mL}$ of BBLTMTM Trypticase ${ }^{\mathrm{TM}}$ soy broth (TSB, BD Biosciences, Franklin Lakes, NJ, USA) and cultivated for about 16 hours on a stirring machine at $250 \mathrm{rpm}$ and $37^{\circ} \mathrm{C}$. Centrifugation later gathered body tissues $(8,000 \times \mathrm{g}$ for $10 \mathrm{~min})$. The less restraining focus of HACC against methicillin-restrainer S. epidermidis (ATCC 35984), S. aureus 376, and S. epidermidis 389 were decided by a microtiter broth density weakening approach as formerly mentioned $(29,34,35)$.

\section{Bacterial adhesion trial using the diffusion plate method}

The diffusion board approach was adopted to decide the bacterial sticking of different diameters on smooth Ti and NT-A, confirmed otherwhere $(36,37)$. The inocula of the three restrainers were stopped again to an ultimate solution of $1 \times 10^{6}$ area shaping units (CFUs) $/ \mathrm{mL}$ in TSB with McFarland criteria. The NT-A plates of different diameters and smooth Ti were stirred at $100 \mathrm{rpm}$ for $6 \mathrm{~h}$ and incubated with $1 \mathrm{ml}$ of the stopping in a 48-well board at $37^{\circ} \mathrm{C}$. Then, we utilized sterile forceps to take out the specimens, put into a new 48-well board, and mildly removed with non-bacteria $\mathrm{PBS}$ three times to take away freely stuck bacteria. We then placed the samples in $0.5 \mathrm{~mL}$ of TSB, and the sticking bacteria on the boards were removed in a $150 \mathrm{~W}$ ultrasonic shower (B3500S-MT, Branson Ultrasonics Co., Shanghai, China) working at $50 \mathrm{~Hz}$ with ultrasonication $(5 \mathrm{~min})$. With that ultrasonication, rapid vortex blending (Vortex-Genie 2, Technological Field, Bohemia, NY, USA) at most fuel was kept for 1 min to take away bacteria that had stuck to the faces. This design is regarded to be available for eliminating biomaterial-stuck bacteria $(38,39)$. The vortex substance was galvanized in three times enlarged onto TSA and later cultivated at $37^{\circ} \mathrm{C}$ for 24 hours. We calculated the amount of CFUs on the TSA and the number of bacteria sticking on the bases, which was manifested concerned with the outer layer of the specimen (CFUs $\left./ \mathrm{mm}^{2}\right)$.

\section{Biofilm formation analysis using the tissue culture plate (TCP) method}

The TCP analysis approach has been regarded as the authoritative check for the detection of biofilm formation $(40,41)$. In brief, the samples were bred with bacterial obstacles of $1 \times 10^{6} \mathrm{CFU} \mathrm{s} / \mathrm{mL}$ in TSB for 48 and 72 hours. A control group of another 48-well board, including samples and TSB, was adopted as the passive comparison. The specimens were lightly rinsed with PBS three times to end loosely-swimming planktonic bacteria. The biofilms shaped on the samples was exsiccated at $60{ }^{\circ} \mathrm{C}$ for 1 hour and dyed with $200 \mu \mathrm{L}$ of a $0.1 \%$ $(\mathrm{wt} / \mathrm{vol})$ the aqueous substance of crystal violet (CV) in the housing for $5 \mathrm{~min}$. The specimens were washed twice with deionized liquid to end superfluous mark. After baking at $37^{\circ} \mathrm{C}$ for $2 \mathrm{~h}$, the biofilm formation shaping on the outer layer was taken a biofilm formation on the surfaces was calculated by the dissolution of the $\mathrm{CV}$ dye in $200 \mu \mathrm{L}$ of $30 \%$ (wt/vol) ice acetic acid for $10 \mathrm{~min}$ with a stir at $300 \mathrm{rpm}$. The wavelength of CV focus was confirmed at $492 \mathrm{~nm}$ (42). The average intake got from the middle restrain well was taken away from the check light-absorbing functions.

\section{Cell culture and characterization}

Experiments were performed under a project license [No. SYXK (Fujian) 2009-0001] granted by the Experimental Animal Ethics Committee of Fujian University of Traditional Chinese Medicine, in compliance with the "Guiding Opinions on the Good Treatment of Laboratory Animals" issued by the Ministry of Science and Technology of the people's Republic of China. Four-week-old male Sprague-Dawley (SD) rats (160-200 g) were provided by Shanghai SLAC Laboratory Animal Co., Ltd. [No. SCXK (Shanghai) 2012-0002]. The culture method of mesenchymal stem cells (MSCs) of Sprague-Dawley (SD) rats was recorded in our previous paper (17). Shortly, body tissues were cultivated in $\alpha$-Repaired Eagle's Middle $(\alpha-M E M)$ culture medium added with $10 \%$ fetal bovine serum (FBS) and $1 \%$ antibiotics (penicillin $100 \mathrm{U} / \mathrm{mL}$, streptomycin sulfate $100 \mu \mathrm{g} / \mathrm{mL}$; GibcoBRL, Grand Island, NY, USA). The body tissues were cultured at $37^{\circ} \mathrm{C}$ in a dampair of $5 \% \mathrm{CO}_{2}$, and the development agent was replaced every 48 hours. When the cultivation reached about $80 \%$ fusion, the MSCs were isolated with $0.25 \%$ trypsin and subcultured. We selected body tissues at access 3 to the test. Subsequently, the cells were sorted by use of a FACSCalibur flow cytometer (BD Biosciences) with 
markers specific for CD29, CD90 and CD45 to identify and acquire pure SD rats MSCs (43). The findings demonstrated that SD rats MSCs were mainly positive for CD90 and CD29 and negative for CD45 as expected.

\section{Measurement of cell attachment}

Smooth Ti, NT, and NT-A were put in 48 well boards (Costar3548, USA), and the MSCs were sowed at a solution of $2 \times 10^{4} /$ well. A control group of another board, including the $\alpha$-MEM cultivation agent and the samples, was adopted as a similar comparison. After hatching 6, they were put together for $12 \mathrm{~h}$ at $37{ }^{\circ} \mathrm{C}$ in a damp environment of $5 \%$ $\mathrm{CO}_{2}$ and $95 \%$ air, $100 \mu \mathrm{L}$ of 3-(4,5-dimethylthiazol-2-yl)2,5-diphenyltetrazolium bromide substance (MTT, SigmaAldrich) into each well. Subsequently, the discs were hatched at $37^{\circ} \mathrm{C}$ for $4 \mathrm{~h}$. Then the supernatant was set aside, and $1 \mathrm{~mL}$ of dimethyl sulphoxide (DMSO, Sigma-Aldrich) was put into the wells for $5 \mathrm{~min}$ to weaken the formazan salts. The discs were understood at $570 \mathrm{~nm}$ with a self-moved disc machine (Synergy HT multidetection microplate). The average light-absorbing got from the middle-restraining well was decided to form the check intake functions. Similarly, at every period, we immobilized and stained the attached cells with 4',6'-diamidino-2-phenylindole (DAPI, Sigma). The body tissues were recorded with a fluorescence microscope (Leica Microsystems, Heidelberg, Germany).

\section{Measurement of cell proliferation}

The MSCs were inoculated on the samples put into 48-well discs with a density of $5 \times 10^{3}$ alive body tissues. Another disc, including the $\alpha$-MEM cultivation agent and the samples, was adopted as a similar restraining. After cultivating for 1 , 4 , and 7 days, we determined the cell proliferation on the specimens by the MTT analysis. Shortly, at every period, $100 \mu \mathrm{L}$ of the MTT substance was placed to each specimen and hatched at $37^{\circ} \mathrm{C}$ for 4 hours. The formazan was later weakened with DMSO. The absorption was determined at $570 \mathrm{~nm}$. The average light absorption obtained from the agent restraining well was measured from the check absorption functions.

\section{Observation of cell morphology}

The body tissue structure of the MSCs was researched with confocal laser scanning microscopy (CLSM). After proliferating for $24 \mathrm{~h}$ with the samples as stated before, the body tissues on the outer layer of the samples were washed mildly with PBS three times, and the sticking body tissues were set with $3.7 \%$ formaldehyde for $15 \mathrm{~min}$ and later dealt with $0.1 \%$ Triton $\mathrm{X}-100$ for another $15 \mathrm{~min}$. The filamentous actin the cytoskeleton in the human marrowderived mesenchymal stem cells (hMSCs) was then stained with Alexa Fluor 555 phalloidin (Molecular Probe, SigmaAldrich) for $1 \mathrm{~h}$, and the cell nuclei were stained with DAPI for $10 \mathrm{~min}$. The specimens were swilled lightly with PBS around every procedure. CLSM was used to visualize the morphology and proliferation of the cell.

\section{Statistical analysis}

All the tests were repeated for three times. The outcome is revealed with a mean \pm standard deviation. The single assay of factor and least meaning variance post hoc checks were adopted to confirm the layer of meaning; $\mathrm{P}<0.05$ was understood as evident, and $\mathrm{P}<0.01$ was defined as evident. The data assays were conducted with SPSS software version 20.0.1 (SPSS Inc., Chicago, IL, USA).

\section{Results}

\section{Morphological characteristics of NT and NT- $A$}

Figure 1 (first column) reveals SEM graphs of TNTs with various inner lengths (50 and $100 \mathrm{~nm}$ ). As mentioned above, the diameter of nanotubes can be managed by changing the anodization parameters. In this research, nanotubes with diameters of 50 and $100 \mathrm{~nm}$ were fabricated using anodization voltages of 15 and $20 \mathrm{~V}$, from different angles. Figure 1 (second column) reveals SEM graphs of two different diameter nanotubular faces placed with andrographolide. The nanotubular structures with andrographolide incorporated into the nanotubes were kept on the surfaces of the drug-loaded specimens.

\section{Loading efficiency of andrographolide in different diameter nanotubes}

As mentioned before, this study used means of a desivac method and vacuum drying to load andrographolide into nanotubes and filled $2 \mathrm{mg}$ of andrographolide into the nanotubes. The holding productivity of andrographolide in the nanotubes was assessed before the launch experiment of andrographolide and it was found that the productivity of andrographolide in nanotubes with different diameters was similar. The previously mentioned HPLC method was 

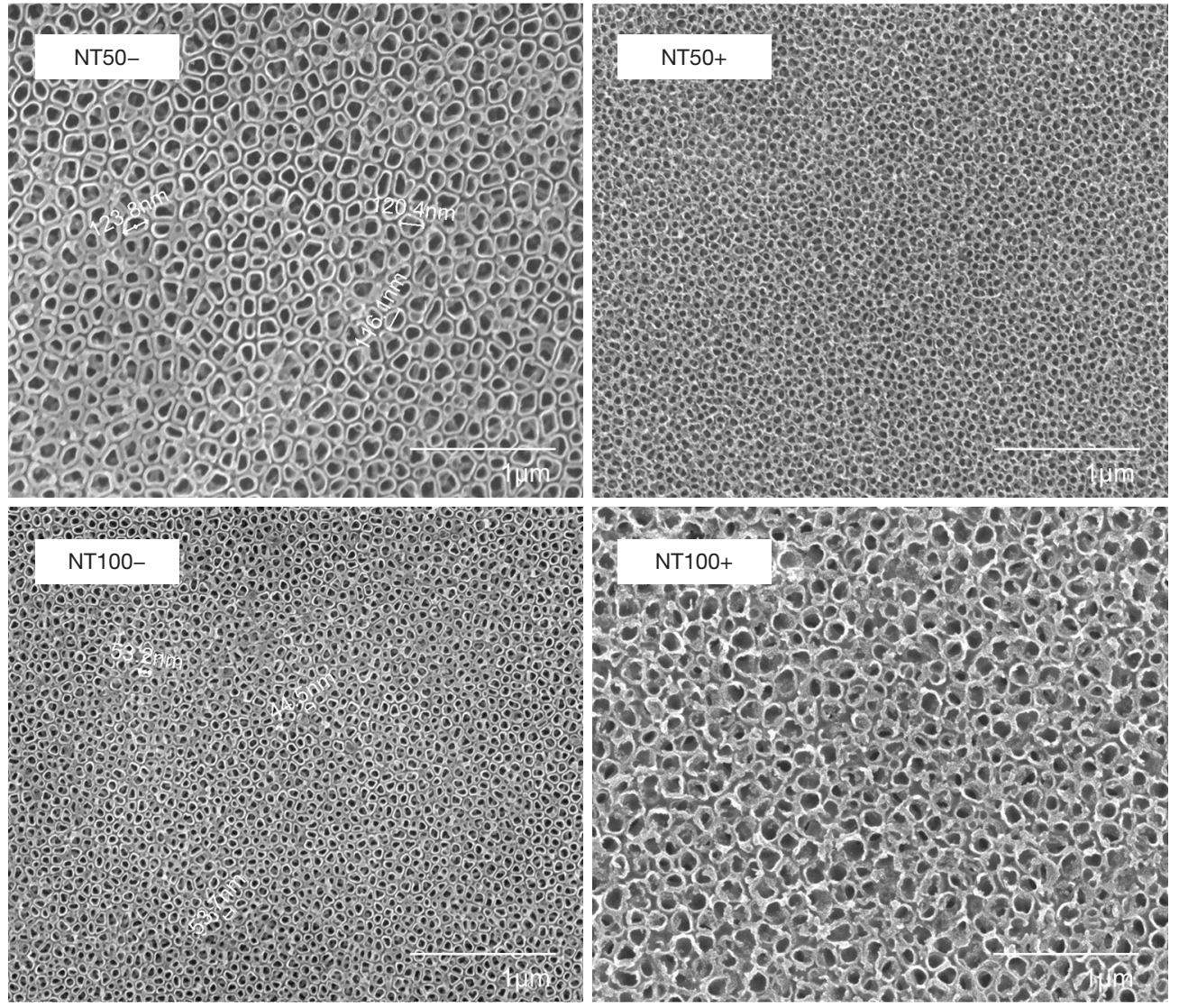

Figure 1 Morphological surfaces of different diameter nanotubular (first column) and andrographolide-loaded nanotubular (second column) were characterized by scanning electron microscopy. The scanning electron microscopy images show the tube diameters were 50 and 100 nm, respectively. The zoom-in level is $\times 30,000$, and the plotting scale is $1 \mu \mathrm{m}$. NT-, nanotubes; NT+, andrographolide-loaded nanotubes.

used to determine the concentrations of the rinse solutions. The loading efficiency of the calculation formula of $\eta=$ (mo $-\mathrm{mr}) / \mathrm{mo}$, where $\eta$ is the holding productivity, mo is the quantity of andrographolide held in the nanotubes $(2 \mathrm{mg})$, and $\mathrm{mr}$ is the quantity of andrographolide in the washing substance. Figure $2 \mathrm{~A}$ reveals the holding productivity of NT-A with various diameters. The outcomes show that $75-80 \%$ of andrographolide is persisted in the nanotubes after the first washing handling. The NT-A in two different diameters did not statistically significantly differ $(\mathrm{P}>0.05)$.

\section{Andrographolide Release from the nanotubes}

Figure $2 B$ indicates that andrographolide launch from the nanotubes with two different diameters, specified in $\mu \mathrm{g} / \mathrm{mL}$. The nanotube with a larger diameter $(100 \mathrm{~nm})$ has a higher sustained release rate of andrographolide than that with a smaller diameter $(50 \mathrm{~nm})$. Most of the andrographolide was released from NT-A100 NT-A50 after about $24 \mathrm{~h}$. We observed that andrographolide release from NT-A consisted of two components: first explosive launch and comparatively launch without much speed. After a careful first launch, the quantity of andrographolide dyed from the nanotubes kept almost continuous.

\section{The MICs of the bacterial strains}

As indicated in Table 1, the MICs of andrographolide were 32,32 , and $32 \mu \mathrm{g} / \mathrm{mL} v s$. ATCC $35984, \mathrm{~S}$. aureus 376, and S. epidermidis 389 , in a different angle. The results showed that the three tested strains were sensitive to andrographolide.

\section{Inbibition of bacterial adbesion and biofilm formation on the NT- $A$}

We used the diffusion plate method to determine the 

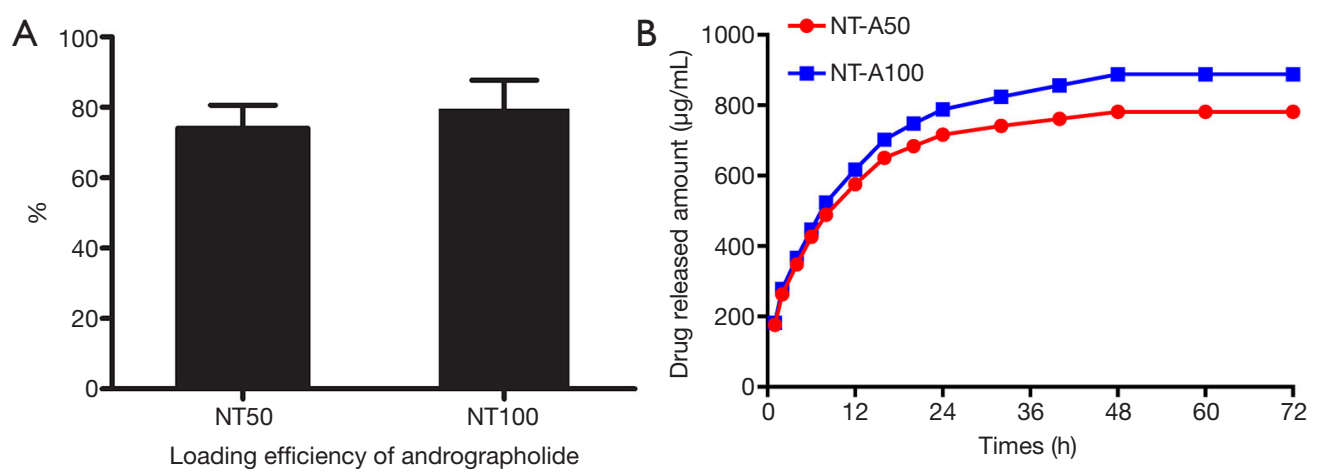

Figure 2 Loading efficiency and drug release profiles of andrographolide. (A) Loading efficiency of andrographolide in different diameter nanotubes. There was no statistically significant difference between NT-A50 and NT-A100 (P>0.05). (B) Accumulated drug release profiles from different diameter nanotubes loaded with $2 \mathrm{mg}$ of andrographolide, expressed in $\mu \mathrm{g} / \mathrm{mL}$. After a high first release, the amount of andrographolide eluted from the nanotubes was constant. NT-A, andrographolide-loaded nanotubes.

Table 1 The minimum inhibiting concentrations (MIC) of the three tested strains

\begin{tabular}{lc}
\hline Microorganism & MIC $(\mu \mathrm{g} / \mathrm{mL})$ \\
\hline ATCC 35984 & 32 \\
S. aureus 376 & 32 \\
S. epidermidis 389 & 32 \\
\hline
\end{tabular}

numbers of living bacteria that stuck to NT-A at the 6,12 , and $24 \mathrm{~h}$ time points. As indicated in Figure 3, NT-A showed significantly fewer numbers on the surface of viable bacteria of the three tested strains than the smooth $\mathrm{Ti}(\mathrm{P}<0.01)$, and there was no significant difference between NT-A50 and NT-A100 ( $>0.05)$. The biofilm formation shaping of the three trial restrainers on the samples was evaluated by crystal-violet marking with the TCP approach. As indicated in Figure 4, significantly decrease the A492 values of the three trial strains were observed on NT-A compared with good $\mathrm{Ti}$ at the 48 and $72 \mathrm{~h}$ time holes $(\mathrm{P}<0.01)$, which indicates nearly no biofilm formation on NT-A outer layers. For the $\mathrm{A}_{492}$ functions of ATCC 35984 , S. aureus 376 , and S. epidermidis 389 , like the bacterial sticking outcomes from the diffusion board test, no distinction of NT-A samples with various inner length at the three-time holes was demonstrated in the present experiment $(\mathrm{P}>0.05)$.

\section{Proliferation of MSCs}

The MTT assay was used to determine cell adhesion and proliferation. As indicated in Figure 5, the production proportion of body tissues on smooth Ti was lower than that on NT and NT-A at different time holes $(\mathrm{P}<0.01)$. The body tissues on NT100 indicated significant production proportion contrasted with those on NT50 at day 4 and day $7(\mathrm{P}<0.05)$. The body tissue production-proportion on NT100 rose to observably contrasted to NT50 at day 7 $(\mathrm{P}<0.05)$. There was no significant distinction between NT and NT-A from data with the same inner length, which was like the adhesion condition of cells.

\section{Cell morphology of MSCs}

Figure 6 shows the MSCs showed markedly different shapes on the smooth Ti surface and the surfaces of a nanotube (NT and NT-A). The body tissues on the nanotube outer layers showed polygonal and gathering elements. However, on the morphology of smooth $\mathrm{Ti}$, the cells are spindle and spherical, with poor diffusion. The output of the body tissues on NT100 was more widespread than that on NT50. The body tissues on the NT-A displayed a similar diffusion outline to those on the NT of the same inner length. Besides, the $100 \mathrm{~nm}$ nanotubes showed higher cell densities on the surfaces compared with the $50 \mathrm{~nm}$ nanotubes and the smooth Ti.

\section{Discussion}

Our results proved that andrographolide could significantly inhibit biofilm formation without cytotoxicity. We prepared TNTs with different diameters by electrochemical anodic 

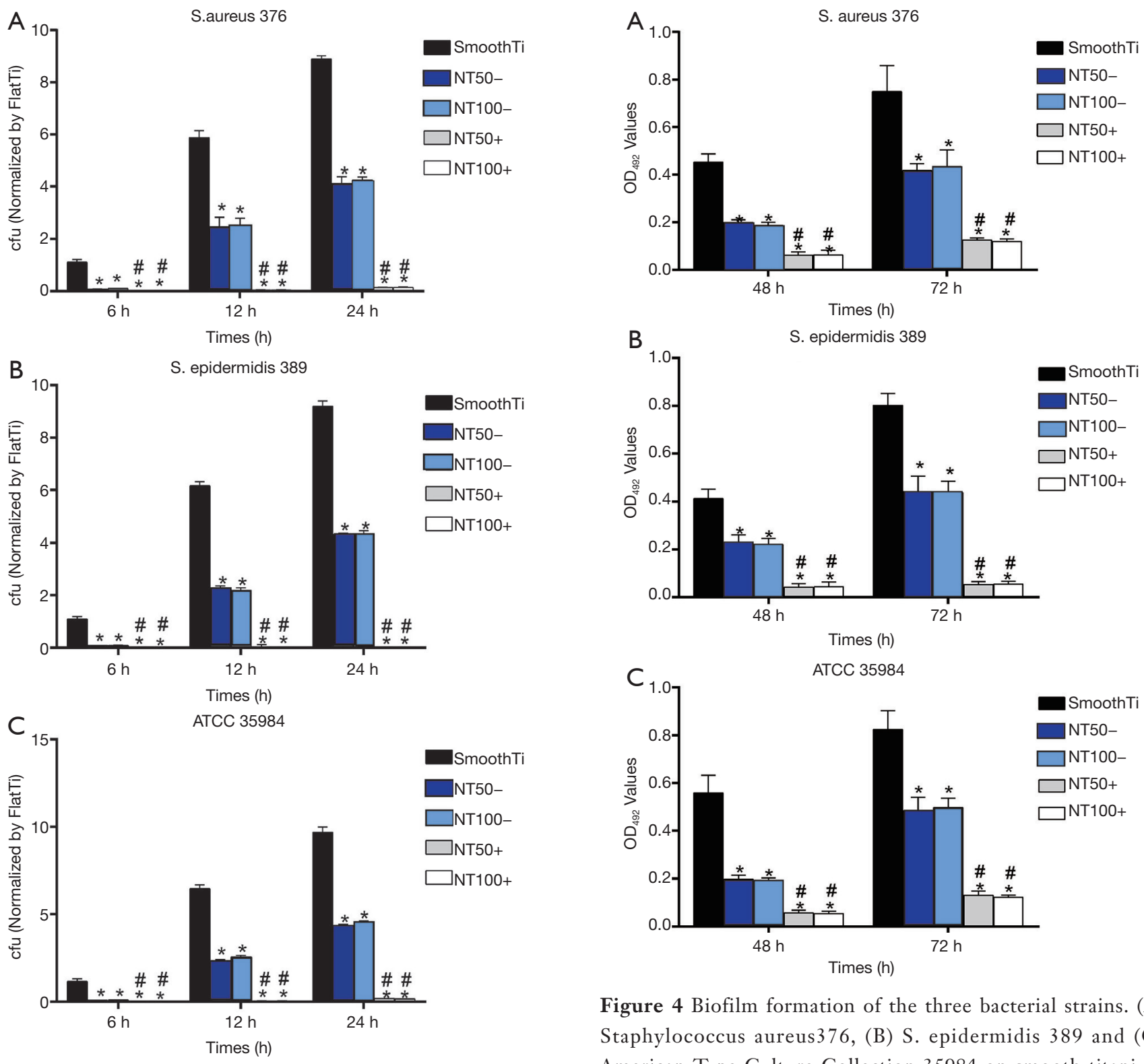

Figure 4 Biofilm formation of the three bacterial strains. (A) Staphylococcus aureus376, (B) S. epidermidis 389 and (C) American Type Culture Collection 35984 on smooth titanium (smoothTi), nanotubes with no drug loading (NT-), and andrographolide-loaded nanotubes (NT+) surfaces at 48 and 72 hours, as detected by the tissue culture plate method. * , denotes a significant difference compared to smooth $\mathrm{Ti}(\mathrm{P}<0.01)$; ${ }^{\text {, denotes }}$ a significant difference compared to NT50- and NT100- $(\mathrm{P}<0.01)$. The data are representative of the results from three independent experiments and are expressed as mean \pm standard deviation. normalized to the counts from the smoothTi control for every bacterial strain. *, denotes a significant difference compared to smooth Ti $(\mathrm{P}<0.01)$; ${ }^{\#}$, denotes a significant difference compared to NT50- and NT100- $(\mathrm{P}<0.01)$. The data are representative of the results from three independent experiments and are expressed as mean \pm standard deviation. cfu, colony-forming unit. 


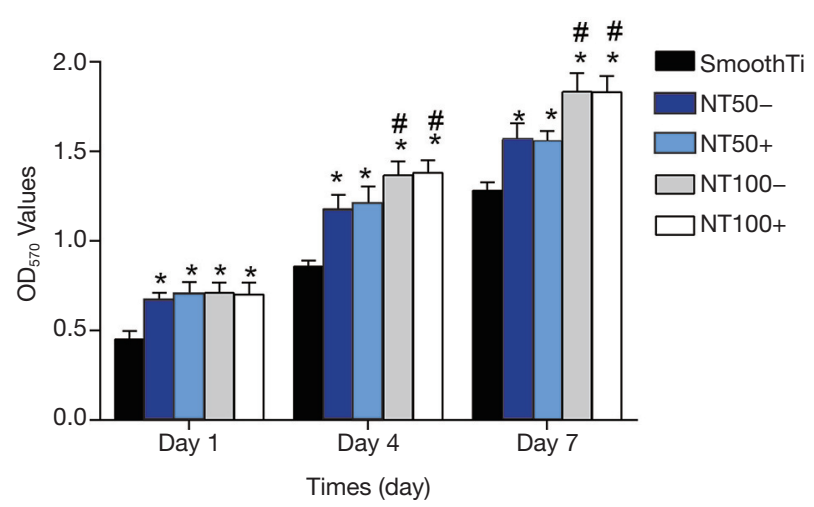

Figure 5 Attachment and proliferation of the mesenchymal stem cells on the surfaces of different samples. *, denotes a significant difference compared to smooth titanium (smoothTi) $(\mathrm{P}<0.01)$; \#, denotes a significant difference compared to NT50- and NT50+ $(\mathrm{P}<0.01)$. NT-, nanotubes; NT+, andrographolide-loaded nanotubes. oxidation in our former research, and nanotubes were stuffed with andrographolide with a desivac approach and vacuum dehydrating to carry out nearby sending in this research.

Once the biofilm is formed, it is particularly hard to remove $(44,45)$. It is speculated that biofilms promote antibiotic restraining at the lowest of the three systems: hindered antibiotic invasion through the extracellular polymeric material, an enabling setting within the internal place, and bacteria tissue specification and role particularity offering rising defense (46). In antibiotics, pathogenic bacteria are competent for surviving in a biofilm at conditions that are 1,000-fold greater than those required to eliminate a planktonic syngen (47).

The first sticking of a microorganism to artificial material outer layers is the crucial cause for the pathogenesis of exogenous body diseases (48). Inhibiting bacterial sticking within the first $6 \mathrm{~h}$ time after entering is essential to prevent


Figure 6 Representative images of the mesenchymal stem cells stained with rhodamine-phalloidin for the actin filaments (red) and nuclei counterstained with DAPI (blue). Shown are the cytoskeletal morphologies of the cells on the surfaces of the smooth titanium (smoothTi), nanotubes with no drug loading (NT-), and andrographolide-loaded nanotubes (NT+). The cells on the nanotubular surfaces showed polygonal and clustering morphology, while those on the smoothTi surface displayed a spindle and spherical morphology. The plotting scale is $1 \mu \mathrm{m}$. 
implant-associated infection (49). Studies have shown that if the antibiotics or other antimicrobials be capable of reducing first bacterial attachment to outer layers, the afterward procedure of biofilm formation would also be restrained (50). Hence, inhibiting bacterial adhesion before biofilm formation plays a vital role in preventing implantassociated infection.

The first outbreak of launch in a total of three teams of NT-A with various inner lengths can be obtained from Table 1 . The high initial concentrations of released andrographolide can eliminate almost all planktonic bacteria to reduce the probability of bacterial sticking on the nanotube's outer layer and the whole quantity of andrographolide launched from NT-A50. Furthermore, NT-A100 within $60 \mathrm{~h}$ were 864 and $768 \mu \mathrm{g}$, in a different angle, which was higher than the MICs of each team of trial restrainers $(32 \mu \mathrm{g} / \mathrm{mL}$ for ATCC 35984 , $32 \mu \mathrm{g} / \mathrm{mL}$ for S. aureus 376 , and $32 \mu \mathrm{g} / \mathrm{mL}$ for $\mathrm{S}$. epidermidis 389). As mentioned formerly, the diffusion board approach and organization civilization tray were utilized to determine the capability of NT-A with various inner lengths to combat bacterial sticking and biofilm formation for three trial restrainers, ATCC 35984, S. aureus 376, and S. epidermidis 389. Our outcomes showed that NT-A could observably inhibit the bacterial adhesion of all three trial strains, including MRSA, and no biofilm formed on the NT-A outer layers at various periods. Contrasted with the NT-A, bacteria adhering to the smooth Ti surface of three trial strains was significantly higher at 6,12 , and $24 \mathrm{~h}$ time points and apparent biofilm was formed at 48 and $72 \mathrm{~h}$ time points.

Analogously to NT-G, these outcomes demonstrated that the greater the inner lengths of the NT were, the higher the antibacterial event would be, due to the longer andrographolide release time of the NT with larger diameters. Our previous study observed that the first sticking and area of S. epidermidis on the outer layers of nanotubes, particularly on the $80 \mathrm{~nm}$ nanotubes, were remarkably decreased compared with the control specimens (51). Besides, another lecture also described the empty nanotubes with four various inner lengths have a satisfactory antibacterial event, and the nanotubes with 80 or $120 \mathrm{~nm}$ diameters showed better antibacterial capability contrasted those with 160 or $200 \mathrm{~nm}$ inner length (15).

\section{Conclusions}

Our in vitro research showed that andrographolide-held nanotubes could greatly increase stem-tissue sticking, productivity, diffusion, and osteogenic specification, and the andrographolide launched from the nanotubes had no harmful influence on the roles of the MSCs. Andrographolideloaded nanotubes also remarkably combat outer layer biofilm formation shaping by staphylococci, which includes antibioticrestrained staphylococci. While nanotubes with no medicine holding also show middle antibacterial properties. Thus, nanotubes-based nearby sending of antibiotics is a promising skill for fighting implant-involved infection.

\section{Acknowledgments}

Funding: This work was supported by the Natural Science Foundation of Fujian Province, China (Grant No. 2017J01333).

\section{Footnote}

Reporting Checklist: The authors have completed the MDAR reporting checklist. Available at http://dx.doi.org/10.21037/ atm-20-4901

Data Sharing Statement: Available at http://dx.doi. org/10.21037/atm-20-4901

Conflicts of Interest: All authors have completed the ICMJE uniform disclosure form (available at http://dx.doi. org/10.21037/atm-20-4901). The authors have no conflicts of interest to declare.

Ethical Statement: The authors are accountable for all aspects of the work in ensuring that questions related to the accuracy or integrity of any part of the work are appropriately investigated and resolved. All procedures of this investigations were conducted under approved protocols of Fuzhou Second Hospital Affiliated to Xiamen University (Fuzhou, China) Institutional Review Board. All animal experiments were performed in accordance with the guidelines for animal care and approved by the Experimental Animal Ethics Committee of Fujian University of Traditional Chinese Medicine [No. SYXK (Fujian) 2009-0001].

Open Access Statement: This is an Open Access article distributed in accordance with the Creative Commons Attribution-NonCommercial-NoDerivs 4.0 International License (CC BY-NC-ND 4.0), which permits the noncommercial replication and distribution of the article with the strict proviso that no changes or edits are made and the original work is properly cited (including links to both the formal publication through the relevant DOI and the license). 
See: https://creativecommons.org/licenses/by-nc-nd/4.0/.

\section{References}

1. Lee KJ, Goodman SB. Identification of periprosthetic joint infection after total hip arthroplasty. J Orthop Translat 2014;3:21-5.

2. Fowler TJ, Sayers A, Whitehouse MR. Two-stage revision surgery for periprosthetic joint infection following total hip arthroplasty. Ann Transl Med 2019;7:S261.

3. Gulati K, Aw MS, Findlay D, et al. Local drug delivery to the bone by drug-releasing implants: perspectives of nano-engineered titania nanotube arrays. Ther Deliv 2012;3:857-73.

4. Park J, Bauer S, Schlegel KA, et al. TiO2 nanotube surfaces: $15 \mathrm{~nm}$--an optimal length scale of surface topography for cell adhesion and differentiation. Small 2009;5:666-71.

5. Lin L, Wang H, Ni M, et al. Enhanced osteointegration of medical titanium implant with surface modifications in micro/nanoscale structures. J Orthop Translat 2014;2:35-42.

6. Crawford GA, Chawla N, Das K, et al. Microstructure and deformation behavior of biocompatible $\mathrm{TiO} 2$ nanotubes on titanium substrate. Acta Biomater 2007;3:359-67.

7. Fu Y, Mo A. A Review on the Electrochemically Self-organized Titania Nanotube Arrays: Synthesis, Modifications, and Biomedical Applications. Nanoscale Res Lett 2018;13:187.

8. Kumeria T, Mon H, Aw MS, et al. Advanced biopolymercoated drug-releasing titania nanotubes (TNTs) implants with simultaneously enhanced osteoblast adhesion and antibacterial properties. Colloids Surf B Biointerfaces 2015;130:255-63.

9. Liu W, Su P, Chen S, et al. Synthesis of TiO2 nanotubes with $\mathrm{ZnO}$ nanoparticles to achieve antibacterial properties and stem cell compatibility. Nanoscale 2014;6:9050-62.

10. Gao A, Hang R, Huang $X$, et al. The effects of titania nanotubes with embedded silver oxide nanoparticles on bacteria and osteoblasts. Biomaterials 2014;35:4223-35.

11. Huo $\mathrm{K}$, Zhang $\mathrm{X}$, Wang $\mathrm{H}$, et al. Osteogenic activity and antibacterial effects on titanium surfaces modified with $\mathrm{Zn}$-incorporated nanotube arrays. Biomaterials 2013;34:3467-78.

12. Mei S, Wang H, Wang W, et al. Antibacterial effects and biocompatibility of titanium surfaces with graded silver incorporation in titania nanotubes. Biomaterials 2014;35:4255-65.

13. Popat KC, Eltgroth M, Latempa TJ, et al. Decreased Staphylococcus epidermis adhesion and increased osteoblast functionality on antibiotic-loaded titania nanotubes. Biomaterials 2007;28:4880-8.

14. Campoccia D, Montanaro L, Speziale P, et al. Antibioticloaded biomaterials and the risks for the spread of antibiotic resistance following their prophylactic and therapeutic clinical use. Biomaterials 2010;31:6363-77.

15. Hanssen AD. Prophylactic use of antibiotic bone cement: an emerging standard--in opposition. J Arthroplasty 2004;19:73-7.

16. Shi $Z$, Neoh KG, Kang ET, et al. Titanium with surfacegrafted dextran and immobilized bone morphogenetic protein-2 for inhibition of bacterial adhesion and enhancement of osteoblast functions. Tissue Eng Part A 2009;15:417-26.

17. Ghasemzadeh-Moghaddam H, Ghaznavi-Rad E, Sekawi Z, et al. Methicillin-susceptible Staphylococcus aureus from clinical and community sources are genetically diverse. Int J Med Microbiol 2011;301:347-53.

18. Ince A, Schutze N, Karl N, et al. Gentamicin negatively influenced osteogenic function in vitro. Int Orthop 2007;31:223-8.

19. Rathbone CR, Cross JD, Brown KV, et al. Effect of various concentrations of antibiotics on osteogenic cell viability and activity. J Orthop Res 2011;29:1070-4.

20. Duewelhenke N, Krut O, Eysel P. Influence on mitochondria and cytotoxicity of different antibiotics administered in high concentrations on primary human osteoblasts and cell lines. Antimicrob Agents Chemother 2007;51:54-63.

21. Chang Y, Goldberg VM, Caplan AI. Toxic effects of gentamicin on marrow-derived human mesenchymal stem cells. Clin Orthop Relat Res 2006;452:242-9.

22. Pountos I, Georgouli T, Bird H, et al. The effect of antibiotics on bone healing: current evidence. Expert Opin Drug Saf 2011;10:935-45.

23. Gupta S, Mishra KP, Ganju L. Broad-spectrum antiviral properties of andrographolide. Arch Virol 2017;162:611-23.

24. Jiang X, Yu P, Jiang J, et al. Synthesis and evaluation of antibacterial activities of andrographolide analogues. Eur J Med Chem 2009;44:2936-43.

25. Tan WSD, Liao W, Zhou S, et al. Is there a future for andrographolide to be an anti-inflammatory drug? Deciphering its major mechanisms of action. Biochem Pharmacol 2017;139:71-81.

26. Kim J, Lee J, Lee YM, et al. Andrographolide-loaded polymerized phenylboronic acid nanoconstruct for stimuli-responsive chemotherapy. J Control Release 2017;259:203-11.

27. Campoccia D, Montanaro L, Arciola CR. The significance of infection related to orthopedic devices and issues of 
antibiotic resistance. Biomaterials 2006;27:2331-9.

28. Tan H, Peng Z, Li Q, et al. The use of quaternised chitosanloaded PMMA to inhibit biofilm formation and downregulate the virulence-associated gene expression of antibioticresistant staphylococcus. Biomaterials 2012;33:365-77.

29. Peng ZX, Tu B, Shen Y, et al. Quaternized chitosan inhibits icaA transcription and biofilm formation by Staphylococcus on a titanium surface. Antimicrob Agents Chemother 2011;55:860-6.

30. Foraker AB, Walczak RJ, Cohen MH, et al. Microfabricated porous silicon particles enhance paracellular delivery of insulin across intestinal Caco-2 cell monolayers. Pharm Res 2003;20:110-6.

31. Salonen J, Laitinen L, Kaukonen AM, et al. Mesoporous silicon microparticles for oral drug delivery: loading and release of five model drugs. J Control Release 2005;108:362-74.

32. Bergonzi MC, Guccione C, Grossi C, et al. Albumin Nanoparticles for Brain Delivery: A Comparison of Chemical versus Thermal Methods and in vivo Behavior. ChemMedChem 2016;11:1840-9.

33. Tan H, Guo S, Yang S, et al. Physical characterization and osteogenic activity of the quaternized chitosan-loaded PMMA bone cement. Acta Biomater 2012;8:2166-74.

34. Cole AM, Weis P, Diamond G. Isolation and characterization of pleurocidin, an antimicrobial peptide in the skin secretions of winter flounder. J Biol Chem 1997;272:12008-13.

35. Beckloff N, Laube D, Castro T, et al. Activity of an antimicrobial peptide mimetic against planktonic and biofilm cultures of oral pathogens. Antimicrob Agents Chemother 2007;51:4125-32.

36. van de Belt H, Neut D, Schenk W, et al. Staphylococcus aureus biofilm formation on different gentamicin-loaded polymethylmethacrylate bone cements. Biomaterials 2001;22:1607-11.

37. Dunne N, Hill J, McAfee P, et al. In vitro study of the efficacy of acrylic bone cement loaded with supplementary amounts of gentamicin: effect on mechanical properties, antibiotic release, and biofilm formation. Acta Orthop 2007;78:774-85.

38. Sherertz RJ, Raad, II, Belani A, et al. Three-year experience with sonicated vascular catheter cultures in a clinical microbiology laboratory. J Clin Microbiol 1990;28:76-82.

39. Bjerkan G, Witso E, Bergh K. Sonication is superior to scraping for retrieval of bacteria in biofilm on titanium and steel surfaces in vitro. Acta Orthop 2009;80:245-50.
40. Christensen GD, Simpson WA, Younger JJ, et al. Adherence of coagulase-negative staphylococci to plastic tissue culture plates: a quantitative model for the adherence of staphylococci to medical devices. J Clin Microbiol 1985;22:996-1006.

41. Mathur T, Singhal S, Khan S, et al. Detection of biofilm formation among the clinical isolates of Staphylococci: an evaluation of three different screening methods. Indian J Med Microbiol 2006;24:25-9.

42. Greco C, Martincic I, Gusinjac A, et al. Staphylococcus epidermidis forms biofilms under simulated platelet storage conditions. Transfusion 2007;47:1143-53.

43. Sun S, Guo Z, Xiao X, et al. Isolation of mouse marrow mesenchymal progenitors by a novel and reliable method. Stem Cells 2003;21:527-35.

44. Costerton JW, Stewart PS, Greenberg EP. Bacterial biofilms: a common cause of persistent infections. Science 1999;284:1318-22.

45. Davies D. Understanding biofilm resistance to antibacterial agents. Nat Rev Drug Discov 2003;2:114-22.

46. Stewart PS, Costerton JW. Antibiotic resistance of bacteria in biofilms. Lancet 2001;358:135-8.

47. Cerca N, Martins S, Cerca F, et al. Comparative assessment of antibiotic susceptibility of coagulasenegative staphylococci in biofilm versus planktonic culture as assessed by bacterial enumeration or rapid XTT colorimetry. J Antimicrob Chemother 2005;56:331-6.

48. Gristina AG, Hobgood CD, Webb LX, et al. Adhesive colonization of biomaterials and antibiotic resistance. Biomaterials 1987;8:423-6.

49. Neoh KG, Hu X, Zheng D, et al. Balancing osteoblast functions and bacterial adhesion on functionalized titanium surfaces. Biomaterials 2012;33:2813-22.

50. Furneri PM, Garozzo A, Musumarra MP, et al. Effects on adhesiveness and hydrophobicity of sub-inhibitory concentrations of netilmicin. Int J Antimicrob Agents 2003;22:164-7.

51. Peng Z, Ni J, Zheng K, et al. Dual effects and mechanism of $\mathrm{TiO} 2$ nanotube arrays in reducing bacterial colonization and enhancing C3H10T1/2 cell adhesion. Int J Nanomedicine 2013;8:3093-105.

Cite this article as: Feng E, Shen K, Lin F, Lin W, Zhang T, Zhang Y, Lin F, Yang Y, Lin C. Improved osteogenic activity and inhibited bacterial biofilm formation on andrographolideloaded titania nanotubes. Ann Transl Med 2020;8(16):987. doi: 10.21037/atm-20-4901 